\title{
Produção de Geléia Real e Desenvolvimento da Larva de Abelhas Apis mellifera, na Região Semi-Árida de Pernambuco ${ }^{1}$
}

\author{
Maria de Lourdes de Queiroz ${ }^{2}$, Severino Benone Paes Barbosa ${ }^{2}$, Marcílio de Azevedo²
}

\begin{abstract}
RESUMO - Foram analisados dados de produção de geléia real (GR) e peso da larva (PL), em dois apiários nos municípios de Ibimirim e Petrolândia, na região semi-árida do Estado de Pernambuco, nos meses de junho e agosto de 1995, para avaliar o momento de maior acúmulo de GR, nas células reais (realeiras), e acompanhar o desenvolvimento da larva. O delineamento experimental foi o de blocos casualizados. A quantidade de GR acumulada nas realeiras foi avaliada 24, 32, 48, 56 e 72 horas após a transferências das larvas. As análises de variância mostraram efeitos significativos para o tempo de permanência, afetando a produção de GR e o PL, nos dois locais estudados. Foi feito um desdobramento polinomial do efeito de tratamento para se avaliar o momento de maior produção de GL. De acordo com as equações de regressão obtidas, as produções máximas ajustadas de 175,57 mg (Ibimirim) e 183,69 mg (Petrolândia) foram conseguidas com 59 e 54 horas após a transferência das larvas, respectivamente. De acordo com os resultados obtidos, concluiu-se que, em ambos os locais, maiores produções de GR poderão ser obtidas fazendo-se coletas entre 48 e 56 horas após a transferência das larvas. Após esse período, o crescimento da larva é intensificado pelo aumento de consumo de geléia, reduzindo-se a quantidade de GR acumulada nas realeiras.
\end{abstract}

Palavras-chave: Apis mellifera, desenvolvimento larval, geléia real, produto apícola

\section{Royal Jelly Production and Larval Development of Bees Apis mellifera in Semi-Arid Region of Pernambuco, Brazil}

\begin{abstract}
In order to evaluate the best period to collect royal jelly (RJ) from queen cells and study the larval development of Apis mellifera, RJ production and larval weight (LW) were analyzed in Ibimirim and Petrolândia, counties of the semi-arid region of Pernambuco, Brazil. The study was performed in May and June, 1995 and the experimental design was randomized blocks. The RJ collected and the LW after $24,32,48,58$ and $72 \mathrm{~h}$ in relation to larval transfer period were significantly different $(\mathrm{P}<0.01)$ in both locations. Regression equations showed that maximum productions of RJ, $157.57 \mathrm{mg}$ in (Ibimirim) and $183.69 \mathrm{mg}$ in (Petrolândia) were achieved, respectively at 59 and $54 \mathrm{~h}$ after larval transference. The results show the best production could be obtained by collecting RJ between 48 and $56 \mathrm{~h}$ after larval transfer in both locations.
\end{abstract}

Key Words: apiary, Apis mellifera, honey bee products, larval development, royal jelly

\section{Introdução}

A apicultura brasileira é, atualmente, uma das mais importantes do mundo em termos quantitativos e qualitativos, no que se refere à produção de mel. Entretanto, informações a respeito de outros produtos apícolas são quase que totalmente inexistentes, como, por exemplo, a geléia real.

Por outro lado, as atividades especializadas na apicultura como a produção de geléia real, através dos anos, têm alcançado interesse comercial também no Brasil.

No Nordeste brasileiro, as condições de ambiente quanto à diversidade florística, principalmente determinada pelas plantas nativas, o clima tropical e a ausência de defensivos agrícolas propiciam a explora- ção de outras atividades apícolas que não somente a produção de mel. A geléia real apresenta-se como uma alternativa para o pequeno produtor rural, porém, um fator limitante seria as secas prolongadas; no entanto, a falta de floração tem maior efeito na produção de mel e pólen. Em se tratando de geléia real, pode ser efetuada a alimentação artificial, sem comprometer o desenvolvimento normal da colméia.

Nas regiões canavieiras, a produção de geléia real constitui importante fonte de renda alternativa para os apicultores, uma vez que o mel oriundo destas áreas não apresenta bom valor comercial.

De modo geral, a literatura especializada cita que, em abelhas do gênero Apis, a coleta de geléia real se dá em torno de 72 horas após ocorrida a transferência

\footnotetext{
1 Dissertação apresentada pela primeira autora para obtenção do Título de Mestre em Produção Animal.

2 Professor do Departamento de Zootecnia - UFRPE - R. Dom Manoel de Medeiros, S/N - Dois Irmãos, Recife/PE - CEP 52.071-000. E-mail: baid@uol.com.br
} 
da larva. No entanto, isto pode estar relacionado, principalmente, com o local e a época em que ocorre a atividade, o que provavelmente determina variações importantes naprodução de geléia(SANTOS MESSAGE, 1980; WIESE, 1989; CORNEJO et al., 1970).

Dessa forma, a presente pesquisa objetivou avaliar o momento de maior produção de geléia real, a partir da transferência das larvas e, simultaneamente, observar o desenvolvimento larval, na região semi-árida do Estado de Pernambuco.

\section{Material e Métodos}

\section{Localização do experimento}

As pesquisas foram desenvolvidas em dois apiários distintos, localizados nos municípios de Ibimirim (Vale do Moxotó) e Petrolândia (Vale do São Francisco), ambos no Estado de Pernambuco, nos meses de junho e agosto de 1995. As condições climáticas nos dois municípios, referentes à pluviosidade mensal média, temperatura média e umidade relativa do ar foram $259,6 \mathrm{~mm}, 21,40^{\circ} \mathrm{C}$ e $70 \%$ e $158,6 \mathrm{~mm}, 20,30^{\circ} \mathrm{C}$ e $54 \%$, respectivamente.

Tendo em vista a importância da flora para o trabalho das abelhas, durante todo o trabalho experimental, foram identificadas as principais plantas apícolas que se encontravam em floração nos dois municípios.

\section{Manejo das colméias}

Em cada apiário, foram utilizadas cinco colméias recrias, para o experimento, e duas colméias matrizes, para dar suporte às colméias experimentais. Para cada colméia recria, foi utilizada uma tela excluidora de rainhas, separando os quadros em dois grupos de cinco, ficando apenas um dos lados com a rainha.

O quadro porta-cúpula recebeu 20 cúpulas, sendo 10 em cada suporte, totalizando 100 cúpulas por colméia, durante todo o período experimental. As cúpulas utilizadas foram de material plástico, de coloração alaranjada, medindo $9,0 \mathrm{~mm}$ de diâmetro e 11,0 $\mathrm{mm}$ de profundidade.

As pesagens da geléia real e das larvas foram feitas em balança analítica, com precisão de 0,001 g. Antes da transferência das larvas, os quadros com as cúpulas foram introduzidos na colméia, durante 24 horas, para adaptação das abelhas e enceramento das cúpulas. Durante toda a fase experimental, cada colméia recebeu xarope contendo mel (50\%), açúcar (25\%) e água $(25 \%)$, em alimentadores tipo
Boardman. As larvas utilizadas nas transferências, tinham entre 24 e 30 horas de idade, identificadas por meio de marcação de áreas com ovos nos favos das colméias matrizes. Antes da transferência da larva, cada cúpula recebeu pequena gota de uma mistura de água destilada e geléia real, em iguais proporções, sobre a qual a larva foi depositada.

\section{Análise experimental}

$\mathrm{O}$ delineamento experimental utilizado foi o de blocos casualizados, de acordo com o modelo estatístico:

$$
Y_{i j}=\mu+t_{i}+b_{j}+e_{i j}
$$

em que $Y_{i j}$ refere-se às variáveis analisadas (GR, $\mathrm{PL}) ; \mu$, média geral; $\mathrm{t}_{\mathrm{i}}$, tempo após transferência, sendo $\mathrm{i}=24,32,48,56$ e $72 \mathrm{~h} ; \mathrm{b}_{\mathrm{j}}$, blocos que representam as colméias, sendo $\mathrm{j}=1,2,3$, 4 e $5 ; \mathrm{e}_{\mathrm{ij}}$, erro experimental aleatório.

A partir das informações obtidas nas análises de variância, foi feita uma análise de regressão, com desdobramento polinomial para efeito de tratamento. Como ilustração, as determinações dos intervalos de tempo em que ocorrem maior reserva de geléia real e aumento no desenvolvimento da larva foram obtidas pelo cálculo do percentual de desenvolvimento horário $(\mathrm{PDH})$, para cada variável analisada, segundo a seguinte equação:

$$
\text { PHD }=\frac{\left(\frac{\text { VAT }_{n}}{\text { VAT }_{n-1}}-1\right) \times 100}{T_{n}-T_{n-1}}
$$

em que VAT é variáveis analisadas (GR, PL); Tn, tempo de permanência da enxertia; Tn-1, tempo anterior de permanência da enxertia;

\section{Resultados e Discussão}

As porcentagens médias de realeiras aceitas nos municípios de Ibimirim e Petrolândia foram 41,2 e 45,6 , respectivamente. Estes resultados foram superiores aos encontrados por CORBELLA (1985), que relatou percentual de aceitação médio de $17,8 \%$, em dois híbridos de Apis mellifera, no Sul do Uruguai e em Rio Claro-SP. No entanto, GARCIA et al. (1989) e CAMARENA et al. (1986), na Argentina, conseguiram valores médios de 57,75 e $87,55 \%$, respectivamente. Peso médio da geléia real

$\mathrm{Na}$ Tabela 1 são mostrados os resultados das análises de variância para peso médio da geléia real, em mg, nos municípios de Ibimirim e Petrolândia. As médias de produção de geléia real, independente de 
tratamento, foram $118,15 \pm 61,06$ e $121,70 \pm 59,54$ mg, para os municípios de Ibimirim e Petrolândia, respectivamente.

A partir do efeito significativo de tratamento, observado na análise de variância, optou-se por um desdobramento polinomial desse efeito, a fim de se estimar o momento de maior acúmulo de geléia real, após ter ocorrida a transferência da larva.

De acordo com as equações de regressão utilizadas, maiores coletas de geléia real foram obtidas 59 $(175,59 \mathrm{mg})$ e 54 horas $(183,69 \mathrm{mg})$ após a transferência das larvas, em Ibimirim $(-265,194+14,87733 X-$ $\left.0,125538 X^{2}\right)$ e Petrolândia $(-333,944+19,26439 X-$ $0,1792313 X^{2}$ ), respectivamente (Figura 1).

Estes resultados não concordam com CORNEJO et al. (1970), CAMARENA et al. (1986) e GARCIA et al. (1989), que relataram maiores produções de geléia real obtidas 72 horas após a transferência da larva.

Entretanto, os resultados obtidos nesta pesquisa concordam com os apresentados por LEVYet al. (1990), NUNES JR. et al. (1994) e BARBOSA e MARTINHO (1994), que observaram maiores produções de geléia real, de abelhas Apis mellifera, em coletas efetuadas de 44 a 64 horas após a transferência das larvas. Já GARCIA (1992), trabalhando com abelhas africanizadas, relata que a extração da geléia real pode ser realizada em torno de 69 horas após a transferência da larva.

As variações quantitativas de geléia real podem estar relacionadas às condições gerais de cada região e/ou ao manejo utilizado nos experimentos como: tipo de colméia-recria, oferta de alimento, idade da larva,

Tabela 1 - Resumos das análises de variância para peso médio da geléia real $(\mathrm{mg})$

Table1 - Summary of analisys of variance for royal jelly ( $m g$ )

\begin{tabular}{lccc}
\hline $\mathrm{FV}$ & G & \multicolumn{2}{c}{ Quadrado médio } \\
SV & $d f$ & \multicolumn{2}{c}{ Mean square } \\
\cline { 3 - 4 } & & Ibimirim & Petrolândia \\
\hline Blocos & 4 & $2615,510926^{\mathrm{ns}}$ & $224,983886^{\mathrm{ns}}$
\end{tabular}

$\begin{array}{llll}\text { Blocks } & & & \\ \text { Tratamentos } & 4 & 23297,775656^{* *} & 22166,072436 * *\end{array}$

Treatments

$\begin{array}{llll}\text { Resíduo } & 16 & 1366,8911785 & 736,661611\end{array}$

Error

ns Não-significativo $(P>0,05)$.

ns Not significant $(P>.05)$.

** Significativo $(P<0,01)$.

** Significant $(P<.01)$. modelo de cúpula entre outros.

Peso médio da larva

Na Tabela 2 encontram-se os resultados das análises de variância referentes ao peso médio da larva, em mg, nos municípios de Ibimirim e Petrolândia.

As análises de variância, referentes ao peso médio da larva, mostraram diferenças significativas $(\mathrm{P}<0,01)$ entre tratamentos, nos dois municípios. Em ambos os casos, os maiores pesos da larva foram observados após 72 horas da transferência das larvas, em que se observou pesos médios das larvas de 84,04 e $56,76 \mathrm{mg}$, nos municípios de Ibimirim e Petrolândia, respectivamente.

Os resultados obtidos foram superiores aos observados por GARCIA (1992), que encontrou peso médio da larva de $49,90 \mathrm{mg}$, às 72 horas após a transferência da larva. Provavelmente, esses resultados são justificáveis, uma vez que a idade da larva para a transferência pode variar de 12 a 36 horas, após a eclosão do ovo.

Da mesma forma como para a produção de geléia real, optou-se por um desdobramento polinomial do efeito de tratamento, para se avaliar o processo de desenvolvimento da larva, até 72 horas após ocorrida a transferência.

Dessa forma, foram obtidas duas equações de regressão, para os municípios de Ibimirim $(23,814$ $\left.1,45049 X+0,0316873 X^{2}\right)$ e Petrolândia $(4,731$ $\left.0,25139 X+0,0134935 X^{2}\right)$, Figura 2.

Para os municípios de Petrolândiae Ibimirim não houve relatos de menor peso da larva, pelo fato de os mesmos terem ocorrido fora dos tratamentos estabelecidos.

Tabela 2 - Resumos das análises de variância do peso médio da larva, em mg, nos municípios de Ibimirim e Petrolândia

Table 2 - Summary of analisys of variance of larval development $(\mathrm{mg})$, in counties Ibimirim and Petrolândia

\begin{tabular}{lccc}
\hline FV & G & \multicolumn{2}{c}{ Quadrado médio } \\
& $d f$ & \multicolumn{2}{c}{ Mean square } \\
\cline { 3 - 4 } & & Ibimirim & Petrolândia \\
\hline $\begin{array}{l}\text { Blocos } \\
\text { Blocks }\end{array}$ & 4 & $297,139414^{\mathrm{ns}}$ & $27,302174^{\mathrm{ns}}$ \\
$\begin{array}{l}\text { Tratamentos } \\
\text { Treatments }\end{array}$ & 4 & $4842,153964 * *$ & $2022,819114^{* *}$ \\
$\begin{array}{l}\text { Resíduo } \\
\text { Error }\end{array}$ & 16 & 163,6618915 & 35,2315265 \\
\hline
\end{tabular}

ns Não-significativo $(\mathrm{P}>0,05)$

ns Not significant $(P>05)$.

** Significativo $(P<0,01)$.

** Significant $(P<.01)$. 


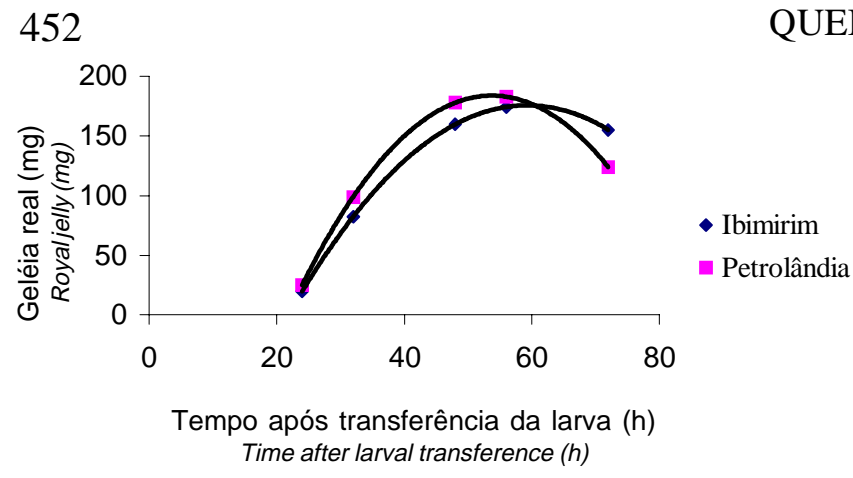

Figura 1 - Produção de geléia real, em função do tempo após transferência da larva.

Figure 1 - Royal jelly production by time after larval transference.

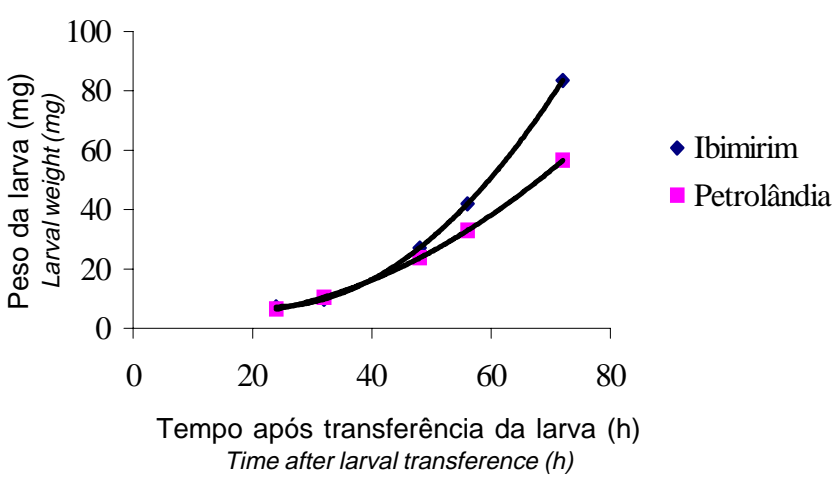

Figura 2 - Peso da larva, em função do tempo após transferência.

Figure 2 - Larval weight by time after transference.

Tabela 3 - Percentual de desenvolvimento horário (PDH) para crescimento da larva e peso da geléia real Table 3 - Percentage of hourly development for larval growth and royal jelly weight

\begin{tabular}{|c|c|c|c|c|}
\hline \multirow[b]{2}{*}{$\begin{array}{l}\text { Tratamento } \\
\text { Treatment }\end{array}$} & \multicolumn{2}{|c|}{ Ibimirim } & \multicolumn{2}{|c|}{ Petrolândia } \\
\hline & $\underset{(\%)}{\mathrm{PDH}_{\text {peso da larva }}}$ & $\begin{array}{c}\mathrm{PDH}_{\text {geléia real }} \\
(\%)\end{array}$ & $\underset{(\%)}{\mathrm{PDH}_{\text {peso da larva }}}$ & $\begin{array}{c}\mathrm{PDH}_{\text {geléia real }} \\
(\%)\end{array}$ \\
\hline $24 \mathrm{~h}$ & - & - & - & - \\
\hline $32 \mathrm{~h}$ & 05,83 & 07,97 & 04,02 & 12,68 \\
\hline $48 \mathrm{~h}$ & 18,09 & 22,05 & 15,60 & 22,52 \\
\hline $56 \mathrm{~h}$ & 23,80 & 21,21 & 18,87 & 21,45 \\
\hline $72 \mathrm{~h}$ & 32,84 & 20,67 & 24,81 & 19,50 \\
\hline
\end{tabular}

* Consideraram-se os valores iniciais para peso da larva e geléia real como $100 \%$.

* The inicial values taken into account for larva and royal jelly weight were $100 \%$.

\section{Percentual de desenvolvimento horário}

Os intervalos dos tempos de permanência da larva na colméia, após ocorrida a transferência, foram de 8 e 16 horas. Para calcular os momentos de maiores reservas de geléia real e de crescimento da larva, o período foi transformado em intervalos de uma hora, que resultou no cálculo do percentual de desenvolvimento horário (PDH), para cada variável analisada.

Na Tabela 3, estão mostrados os valores referentes aos percentuais de desenvolvimento por hora dos pesos da larva e da geléia real, calculados a partir da fórmula desenvolvida neste trabalho, para os dois municípios. Estes valores mostram os momentos em que ocorreram maiores e menores peso da geléia real e desenvolvimento da larva. Nota-se que o desenvolvimento da larva foi maior no município de Ibimirim, entre os intervalos estudados. Provavelmente, as condições climáticas do município de Ibimirim te- nham contribuído, favoravelmente, para os resultados observados naquele município.

Com relação à produção de geléia real, observa-se grande semelhança dos resultados entre os dois municípios. A Tabela 3 mostra que o momento de maior volume de acúmulo de geléia real ocorre 48 horas após a transferência da larva e, depois desse momento, não há mais aumento na disponibilidade de geléia real, provavelmente, determinado pelo crescimento e, em conseqüência, maior consumo pelas larvas.

\section{Conclusões}

Maiores produções de geléia real podem ser obtidas 59 e 54 horas após a transferência das larvas, em Ibimirim e Petrolândia, respectivamente. Por razões práticas de manejo da colméia, sugere-se que a coleta de geléia ocorra 48 horas após a transferência da larva. 
O crescimento da larva é intensificado no terço final do seu desenvolvimento; portanto, coletas de geléia real efetuadas neste período de desenvolvimento da larva serão reduzidas em face do aumento de consumo.

Sugere-se desenvolver pesquisas para avaliar o comportamento da colméia, em coletas de geléia real de 48 em 48 horas.

\section{Referências Bibliográficas}

BARBOSA, S.B.P., MARTINHO, M.R. 1994. Produção de Geléia Real em abelhas Apis mellifera L. Caderno Ômega da Universidade Federal Rural de Pernambuco, Série Zootecnia, Recife, 2:73-80.

CAMARENA, J.E., PECHO, I.M., BARRAL, J.D. Estudio comparado de rendimento cuantitativo de producion de jalea real entre los metodos por hofanizacion y con presencia de reina. In: CONGRESSO BRASILEIRO DE APICULTURA, 7, 1986, Salvador. Programa e Resumo... Salvador: Confederação Brasileira de Apicultura, 1986. p.75.

CORBELLA, E. Aspectos adaptativos e ecológicos da aceitação de larvas transferidas nas abelhas Apis mellifera L. como subsídios para o melhoramento de rainhas e produção de geléia real. Ribeirão Preto, SP: 1985. 109p. Tese (Doutorado em Ciências)-Faculdade de Medicina de Ribeirão Preto, 1985.

CORNEJO, L.G., BARTOLOMÉ, R., ITZCOVICH, B. Costa de production de jalea real, período de 1969/70, en Argentina. In: CONGRESSO BRASILEIRO DE APICULTURA, 1, 1970, Florianópolis. Anais ... Florianópolis: Associação Catarinense de Apicultura, 1970. p.210-216.

COUTO, R.H.N. Geléia real: aspectos gerais de produção e resultados experimentais na região de Jaboticabal (SP). In: CONGRESSO BRASILEIRO DE APICULTURA, 10, 1994. São Paulo. Anais... São Paulo: Confederação Brasileira de Apicultura, 1994. p.116-127.
GARCIA, R.C. Produção de geléia real e desenvolvimento de colonias de albelhas Apis mellifera italiana e seus híbridos com africanizadas, em fecundação natural e instrumental. Jaboticabal: FCAVJ - UNESP, 1992. 257p. Dissertação (Mestrado em Zootecnia) - Universidade Estadual de São Paulo, 1992.

GARCIA, R.C., COUTO, R.H.N., MALERBO, D.T.S. 1989. Efeitos do fornecimento de farelo de trigo sobre o desenvolvimento da glândula hipofaringeana e produção de Geléia Real em colméias de Apis mellifera. Ciência Zootecnica, 4(1):6-8.

LEVY, P.S., BARBOSA, R.M., PARANHOS, B.A.J. Avaliação de desempenhos das abelhas africanizadas na produção comercial de geléia real. In: CONGRESSO BRASILEIRO DE APICUlTURA, 8, 1990. Campos de Jordão. Anais ... Campos de Jordão: Coordenação Técnica e Científica. 1990. p.2.

NUNES JR., R.C., BARBOSA, S.B.P., QUEIROZ, M.L. Produção de geléia real em abelhas Apis mellifera L., em diferentes momentos de coleta. In: SOCIEDADE BRASILEIRA DE ZOOTECNIA, 31, 1994, Maringá. Anais... Maringá: SBZ, 1994. p.593.

SANTOS, J.J., MESSAGE, D. Utilização de mini-recrias para produção de geléia real. In: CONGRESSO BRASILEIRO DE APICULTURA, 5, CONGRESSO LATINO-IBERO-AMERICANO DE APICULTURA, 3, 1980, Viçosa. Anais... Viçosa: Confederação Brasileira de Apicultura, 1980. p.307-11.

WIESE, H. Nova apicultura. 1989. 6.ed. Porto Alegre: Livraria e Editora Agropecuária Ltda. p.488-490.

Recebido em: 02/12/98

Aceito em: 23/01/01 